\title{
Interacciones sexuales en el mundo online*
}

\author{
Jose Maria VALCUENDE DEL RíO** \\ Patricia Rosalba Salvador Moura CosTA*** \\ Maria José MARCO MACARRO****
}

\begin{abstract}
Resumen
El análisis del mercado del sexo y de las prácticas sexuales en internet nos permite reflexionar sobre las transformaciones experimentadas en el ámbito de la sexualidad. Para aproximarnos a esta realidad proponemos un análisis de las web y apps, que adquieren hoy un plano central en las interacciones sexuales, resignificando el mundo offline y con ello la propia significación de la corporalidad y de las prácticas sexuales.
\end{abstract}

Palabras-clave: Mercado del Sexo, Internet, Sexualidad.

* Recebido em 01 de janeiro de 2019, aceito em 09 de abril de 2019.

* Profesor Doctor del Departamento de Antropología Social, Psicología Básica y Salud Pública de la Universidad Pablo Olavide (UPO), Sevilla, España. Área de Antropología Social. imvalrio@upo.es / https://orcid.org/0000-0003-1161-2611

*** Profesora Doctora del Master em Antropologia de la Universidad Federal de Sergipe (UFS), São Cristóvão, SE, Brasil. Área de Antropología Social. patriciarosalba@gmail.com / http://orcid.org/0000-0001-8320-9093

**** Profesora Doctora del Departamento de Antropología Social, Psicología Básica y Salud Pública de la Universidad Pablo de Olavide (UPO), Sevilla, España. Área de Psicología Básica. mmarmac@upo.es / http://orcid.oro/00000003-4620-6146 


\begin{abstract}
The analysis of the sex market and sexual practices found on the internet allows us to reflect on transformations experienced in the field of sexuality. To approach this reality we propose an analysis of the web and apps, which currently have a central role in sexual interactions, resignifying the offline world and with it the very significance of corporality and sexual practices.
\end{abstract}

KeyWord: Sex Market, Internet, Sexuality. 


\section{Introduccíon}

La imagen del ciborg muestra a un humano que no puede ser comprendido sin abordar una realidad extrasomática que forma parte de su corporalidad (Haraway, 1984). Los cuerpos son "en el hacer": actúan y se proyectan en personas, objetos y herramientas (Latour, 2005). Para Escobar (2016:22) "[...] qualquer tecnologia representa uma invenção cultural, no sentido de que ela produz um mundo. Toda tecnología emerge de condições culturais particulares ao mesmo tempo em que contribui para a criação de novas condições culturais".

El cuerpo se extiende y se prolonga en los móviles, ihphones, tablet... ¿Dónde empieza y termina lo corporal, cuál es la frontera entre "lo natural" y "artificial"? Como se pregunta Butler (2002:13) "[...] ¿por qué lo construido se entiende como artificial y prescindible? ¿Qué deberíamos hacer con las construcciones sin las cuales no podríamos pensar, vivir o dar algún sentido, aquellas que de algún modo se nos hicieron necesarias?" Estas "construcciones" permiten adentrarnos en realidades espacio-temporales lejanas, que redefinen nuestros espacios y tiempos más próximos. En la modernidad tardía nuestra cotidianidad es una realidad globalizada (Giddens, 1997); los tiempos se aceleran y las distancias se acortan, diferentes mundos penetran constantemente en nuestras vidas, permitiéndonos la interacción simultánea en ámbitos espaciotemporales múltiples.

Las TIC suponen una reconfiguración del cuerpo y de las interconexiones humanas a través de la ampliación y flexibilización de las redes. "Las redes -o los rizomas- permiten no sólo distribuir la acción, sino además operar las desvinculaciones y las rupturas en la proximidad e inversamente re-vincularnos en la distancia" (Latour et al., 2015:142-143).

La transformación de acciones, tiempos, espacios y vínculos a través de las TIC tiene indudables consecuencias en todos los aspectos de nuestra vida, y también en un aspecto en el que centraremos esta reflexión: las formas de canalizar el deseo. En 
este sentido nos preguntamos ¿Cómo internet y las apps han modificado la significación de las prácticas sexuales? ¿En qué medida el uso de nuevas herramientas modifica las formas de interacción sexual?

Partimos de la imposibilidad de analizar la significación de las prácticas sexuales sin aproximarnos a las herramientas/ contextos en los que los cuerpos se proyectan, en los que también se relacionan. Parece indudable que el acceso al mundo online ha ampliado, por lo menos en teoría, las posibilidades de mantener relaciones sexuales y en todo caso la oferta sexual. También es evidente que la constante exposición en el mundo virtual modificó nuestras formas de representarnos corporalmente. Sin embargo, no podemos comprender la significación de lo que podríamos denominar "oferta corporal y sexual" en el mundo online, sin contextualizar el omnipotente papel del mercado (Celorio, 2009), por lo menos a dos niveles:

1. Internet posibilitó la conformación de negocios e interacciones sexuales globales y la resignificación de los mercados sexuales locales.

2. La constante exposición al mundo online permite acceder a amplios y diferentes mercados sexuales, y convertirnos en "objeto" de consumo.

El análisis de la realidad online está aún en una fase preliminar y más en la relativo a las interacciones sexuales (Miskolci, 2016). De hecho, la mayor parte de la bibliografía que articula ambos aspectos se ha centrado fundamentalmente en el carácter "problemático" y en los riesgos que conlleva el uso de la realidad online, especialmente para los más jóvenes. Son numerosas las investigaciones centradas en fenómenos como el ciberbulling (Sabater y López, 2015; Buelga, Cava y Musitu. 2010; Avilés Martínez, 2009; Ortega et al. 2017), el sexting (Menjibar, 2010; Fajardo et al., 2013) o en los peligros asociados a la difusión de material pornográfico, drogas, violencia, corrupción de menores, adicciones (García Piña, 2008; Jiménez, 2011). 
Un aspecto que está mereciendo una especial atención está relacionado con las formas de expresar la identidad en internet, especialmente en las poblaciones cuya sexualidad no se adecua a la norma. Algunas investigaciones evidencian el papel de internet como ámbito de enunciación para las minorías sexuales. Así sucede con las lesbianas (Pérez Santana, 2013), gais (Miskolci, 2017) y otras sexualidades no normativas. Estas herramientas permiten articularse a colectivos que encuentran en el mundo virtual una forma de reafirmarse y articular estrategias de contestación y resistencia (Clua, 2015). El mundo virtual ha facilitado la expansión de determinados modelos identitarios, reforzando procesos de hibridación entre lo local y lo global (Valcuende del Río y CáceresFeria, 2014), visibilizando fenómenos más o menos ocultos, especialmente en las prácticas más proscritas, entre otras, la pedofilia (Ruiz Torres, 2003) la zoofilia (Coca-Pérez, Cáceres-Feria y Valcuende del Río, 2018; Kavanaugh y Maratea, 2016; Williams y Weinberg, 2003).

Internet se está convirtiendo en un ámbito central de investigación planteándonos nuevos cuestionamientos; pero, más allá de los problemas percibidos socialmente, parece imprescindible repensar de forma global la significación de lo que se ha denominado cibercultura (Segasta y Riofiotis, 2016). En este texto no nos interesa tanto analizar los peligros de internet y las apps, en los que tanto incide la literatura especializada, como reflexionar sobre la lógica que favorece su utilización masiva, y las nuevas dimensiones de unas prácticas sexuales en las que el mundo online y el mundo offline forman parte de un continuum que redefine nuestra corporalidad a diversos niveles. La aproximación a fenómenos como la prostitución, la pornografía y los intercambios sexuales, nos ayudará a comprender las especificidades de las herramientas online y su vinculación con el mercado. 


\section{Aspectos metodológicos}

Para realizar esta investigación analizamos el contenido de algunas web y apps; páginas que ofertan prostitución: Garotos.com.br, Hottrasvestis, Escort-guides; web de pornografía: Pornohub, Joybear, Xvideo; páginas de anuncios no profesionales: Pasión.com; páginas de agencias matrimoniales y de contactos: eDarling, A2 Encontros, Unicis; chats y aplicaciones cuya finalidad es el encuentro sexual: Chueca.com, Grinder, Manhut, Tinder, Scruff, Sudy... aplicaciones cuyo fin es el cibersexo: Dirtyroulette o Cam4, y otras que, aunque supuestamente no están destinadas al intercambio sexual, en la práctica son utilizadas con este fin (Twitter, Facebook). Nuestro análisis se centra en las imágenes ofertadas, a excepción de los chats y de las webs de cibersexo donde hemos podido seguir algunas de las interacciones que se producen. Somos conscientes de las limitaciones de este enfoque, ya que sería fundamental profundizar en próximas investigaciones, no sólo en la emisión de imágenes y mensajes, sino también, en su consumo, sin embargo, consideramos que este trabajo aporta una visión global sobre el mercado sexual en internet, que abre nuevas perspectivas de investigación.

El papel del mercado: todos los mundos al alcance de nuestra mirada

El mercado no es sólo una forma de gestionar el intercambio y la producción, es también un mito encarnado en sociedades cada vez más individualistas. La ventana del ordenador o del móvil nos promete conseguir todo lo imaginable, incluso lo que no habíamos imaginado. Así, por ejemplo, Amazón oferta el mundo de la "A a la Z". Un gran escaparate comercial que puede encontrarse en China, Estados Unidos o a la vuelta de la esquina, y la tienda sin fin penetra nuestro salón, el dormitorio o cuando caminamos por la calle.

Pero la realidad online no es sólo algo que nos muestra productos y nos ofrece posibilidades de forma aséptica. A medida 
que utilizamos internet el mundo al que accedemos es la recreación de nuestro mundo; la imagen de Narciso mirándose en el agua evoca esta ensoñación. Internet es una fábrica de construir fantasías, permitiéndonos soñar con otros cuerpos y recrear nuestro cuerpo imaginado. Y es que tal y como señala Le Breton con relación al cuerpo moderno:

Implica la ruptura del sujeto con los otros (una estructura social de tipo individualista), con el cosmos (las materias primas que componen el cuerpo no encuentran correspondencia en ninguna otra parte) consigo mismo (poseer un cuerpo más que ser su cuerpo). El cuerpo occidental es el lugar de la censura, el recinto objetivo de la soberanía del ego (Le Breton, 2002:8).

La separación del cuerpo del yo posibilita convertir al primero en objeto de consumo, en ámbito de intervención del discurso científico-técnico, pero también del mercado. Ambos discursos fragmentan la corporalidad y por tanto al individuo. La tecno-ciencia, a través de la medicina, por ejemplo, interviene a partir de "la salud" no sobre personas sino sobre hígados, corazones, riñones; el mercado hace lo propio, a partir de la noción de belleza, actuando sobre la alopecia, los michelines, las arrugas... La máxima de la postmodernidad es que un cuerpo "bello" es un cuerpo "sano". El Estado vigila los cuerpos y la salud a la misma velocidad que desregulariza el mercado laboral. Los derechos colectivos pasan a ser entendidos como derechos meramente individuales. Son los individuos los responsables de que su cuerpo no produzca, no sea sano, y la sociedad asume la vigilancia penalizando las corporalidades improductivas, y es que al final la lógica de los costes y beneficios se traslada al control de unos cuerpos que deben reproducir el imaginario de joven, bello y sano (toda una amplia industria se volcará al cuidado corporal). El Estado, la tecnociencia y el mercado se centran precisamente en responsabilizarnos de la fealdad, la enfermedad o de nuestra pobreza. El cuerpo se convierte en campo de batalla para el control (autocontrol) de unos individuos que, al mismo tiempo 
que autoproclaman su autosuficiencia, refuerzan su aislamiento. Ahora los cuerpos tienen nuevas posibilidades a partir de extensiones inorgánicas que permiten acceder a otras corporalidades y reinventar nuestra propia corporalidad. La constante exposición corporal en el mundo online, incide en que la imagen se segmente de nuestra fisicalidad, dando la posibilidad de un constante juego, parafraseando a Recio (1986), de máscaras; el simulacro se transforma en realidad.

Es cierto que en todos los contextos culturales los cuerpos son elaborados en función de la edad, estado civil, clase social, género... "Constituido en la esfera pública como un fenómeno social, mi cuerpo es y no es mío" (Butler, 2006:52). Ahora bien, el mito de la postmodernidad construye cuerpos supuestamente únicos, exclusivos, que a fuerza de singularizarse se parecen cada vez más; unos cuerpos listos para ser mostrados y expuestos, en términos de Le Bretón (2002), "fetichizados".

El uso de la imagen separada del cuerpo no es algo nuevo. La fotografía, por ejemplo, ya permitía la socialización de nuestra imagen (como también lo hacía la pintura o el video). Ahora bien, las fotografías eran algo extraordinario para momentos extraordinarios, que se guardaban en álbumes destinados para el consumo familiar o de los amigos próximos. Los nuevos medios de comunicación han convertido a la imagen en algo central pero al mismo tiempo banal, retransmitida en tiempo real: nuestra última comida, una fiesta, una reunión..., diluyendo las fronteras entre lo íntimo y lo público. Internet supone inevitablemente la pérdida de la privacidad: "¿Privacidad en Internet? Olvídese de eso. Usted ya ha perdido su privacidad para siempre". ¿Qué significa eso? Significa que cualquier cosa que hagamos en la red se puede detectar electrónicamente" (Castell, 2000:15). También significa la colectivización de una imagen reelaborada y pensada para los otros, que adquiere vida propia en un escaparate global, potencialmente abierto veinticuatro horas del día.

En este contexto, la vista (y por tanto la imagen) se convierte en el sentido central por encima de los otros sentidos (el olfato, el gusto, el tacto...). Mientras el cuerpo en cuanto imagen 
gana en relevancia; el cuerpo, en cuanto organismo, con sus propias limitaciones $y$ deficiencias, se convierte en un inconveniente. Como señala Le Bretón (2017) reflexionando sobre el caminar para la gente que tiene prisa en la ciudad, el cuerpo de los otros es un problema porque frena nuestra marcha, de la misma forma que nuestro cuerpo es el impedimento que nos limita llegar a tiempo, toda una metáfora que puede ser aplicada al mundo de la constante inmediatez del mundo online.

Los cuerpos expuestos buscan una representación visual que los singularice, que los convierta en productos "exclusivos" $\mathrm{y} / \mathrm{o}$ "deseables". Internet contribuye a pensarnos constantemente en función de reales o potenciales observadores. La participación en varios escenarios sociales simultáneos, la constante exposición y recepción de información hacen de nuestra identidad un mosaico de imágenes y representaciones. Un flujo continuo e incesante de imágenes, datos, textos, acciones propias y ajenas ponen en jaque antiguas formas de participación en la sociedad (Valcuende del Río; Sierra; Marco-Macarro, 2017). Nuestra forma de mostrarnos en las páginas, los likes o el número de visitas en cierta medida indican nuestra "cotización", por lo que es importante "invertir" tiempo en una suma de representaciones, que mostramos de una forma constante.

\section{Mercado, internet y oferta corporal}

Entre las múltiples cosas y actividades que se ofertan en internet encontramos una amplia y diversificada gama de cuerpos y potenciales relaciones sexuales, a través de la prostitución, la pornografía, el cibersexo... Diferentes formas de intercambio sexual, pagado o gratuito, a las que nos vamos a aproximar en las próximas páginas. 


\section{Trabajo sexual y realidad online}

Algunas investigaciones analizan la incidencia del modelo online en el trabajo sexual (Guasch y Lizardo, 2017). Acceder a diferentes servicios sexuales se puede realizar ahora, sin el riesgo o la incomodidad de desplazarse a determinados lugares, desde la aparente privacidad que proporciona el uso de internet. Este contexto facilita a las trabajadoras y trabajadores sexuales darse a conocer, seleccionar y ser seleccionados por los clientes de forma previa. A su vez, los clientes acceden a las características físicas y servicios ofertados por estos hombres y mujeres, que deben realizar un esfuerzo para personalizar su oferta en un amplísimo mercado, que constantemente busca "novedades" (Guasch y Lizardo, 2017).

Figura 1: "Acompañantes" masculinos

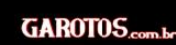
Sầo Paulo Rio de Janeiro Recife Brasilia Belo Horizonte Vitórí Euritiba Porto Alegre Florianćpolis Fortaleza Salvador Goiânia Cuiabá Sầo Luis Joầ Pessoa Manaus Belém Balneárí Camboriú Campinas Santos Soracaba Rỉeirāo Preto 5.J. dos Campos

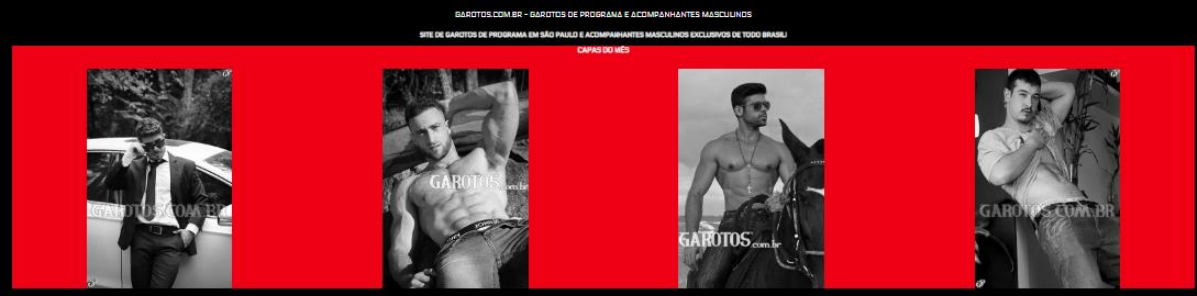

Fuente: Garotos.com (2018).

Con internet se ha ampliado el muestrario de cuerpos y el radio de acción que permite interaccionar en contextos muy diferentes y planificar intercambios sexuales de forma previa. Como señala Piscitelli (2013) el análisis de las web contribuye a la comprensión de la transnacionalización del mercado sexual. Un 
aspecto que estaría incidiendo en algunos destinos turísticos sexuales, al facilitar el contacto sexual de los potenciales clientes.

Figura 2: Web de contactos

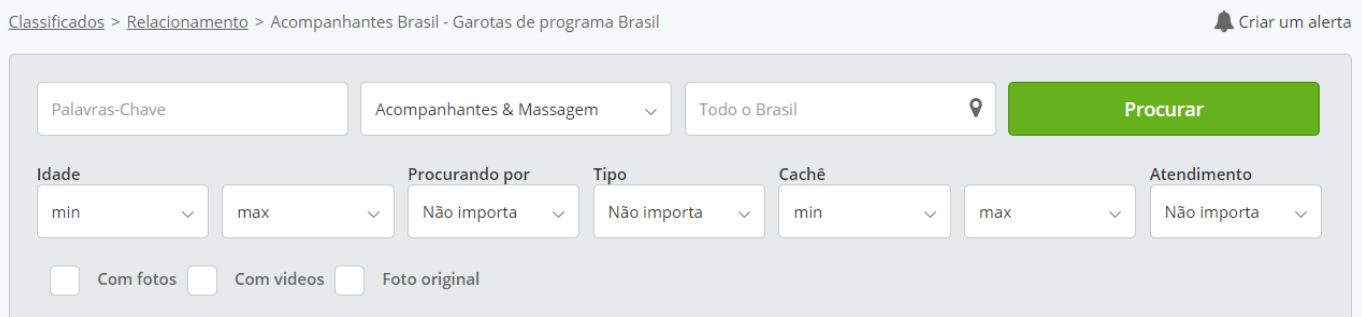

Fuente: Vivalocal (2018).

Las transformaciones que ha generado internet en el ámbito de la prostitución están relacionadas con la posibilidad de acceder a un más amplio mercado sexual, y de la mayor facilidad de los trabajadores-as sexuales de contactar con los clientes de forma directa, modificando la significación de los espacios offline como contextos que propiciaban un primer encuentro. El declive, en algunas ciudades, de clubes, cines $\mathrm{X}$, sexshops... y la reducción de la prostitución callejera se correspondería con una reestructuración del mercado sexual. La disminución de la oferta offline se ha visto acompañada por el incremento de la oferta online, lo que se estaría traduciendo, entre otras cosas, en un debilitamiento de los intermediarios (Guasch y Lizardo, 2017) y propiciando la generación de mecanismos de resistencia de los trabajadores-as sexuales (Clua, 2015).

En cualquier ámbito comunicativo que posibilite el encuentro sexual se pueden encontrar, de forma más o menos explícita, mensajes que buscan obtener beneficios económicos del intercambio sexual, sean chats, páginas de anuncios, foros... Ahora bien, en el mundo online nos encontramos infinidad de páginas de prostitución masculina y femenina, destinadas a diferentes segmentos del mercado. Las páginas que ofertan prostitución tienen características específicas en función de factores 
como el género, la opción sexual, las posibilidades económicas de los clientes.

Figura 3: Páginas de "escort” en Madrid

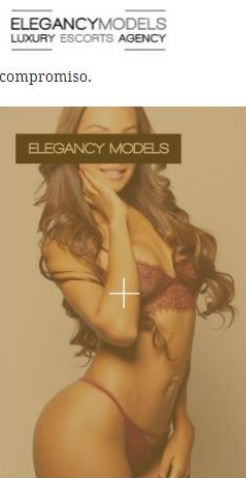

Escort Iris

Fuente: Elegancy Models Luxury Scort Agency (2018).

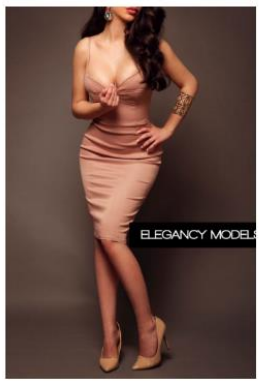

Escort Alma

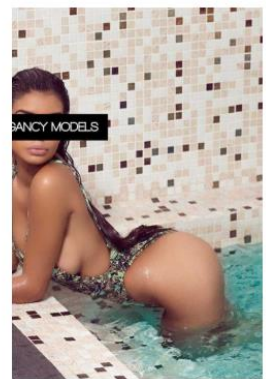

Escort Ines Escort Ines
CONTACTO 1 = ESPAÑOL

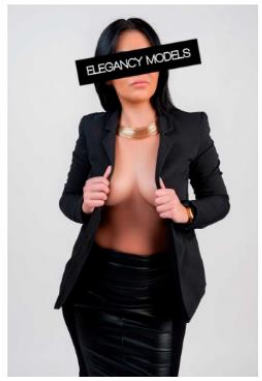

Escort Nicol Madrid

Sin embargo, al igual que en el mundo ofline, en internet habitualmente los límites entre lo que es y no es prostitución es difuso. Los beneficios de los servicios sexuales pueden ir más allá de la prestación de un servicio puntual. Internet ha facilitado la ampliación de una oferta que puede traducirse en diversas opciones, como así sucede con la app Sugar daddy (mujeres que buscan a hombres adinerados, de determinada posición social). 
Figura 4: Sugar Daddy: "amor, dinero y placer" en el mundo de los encuentros online

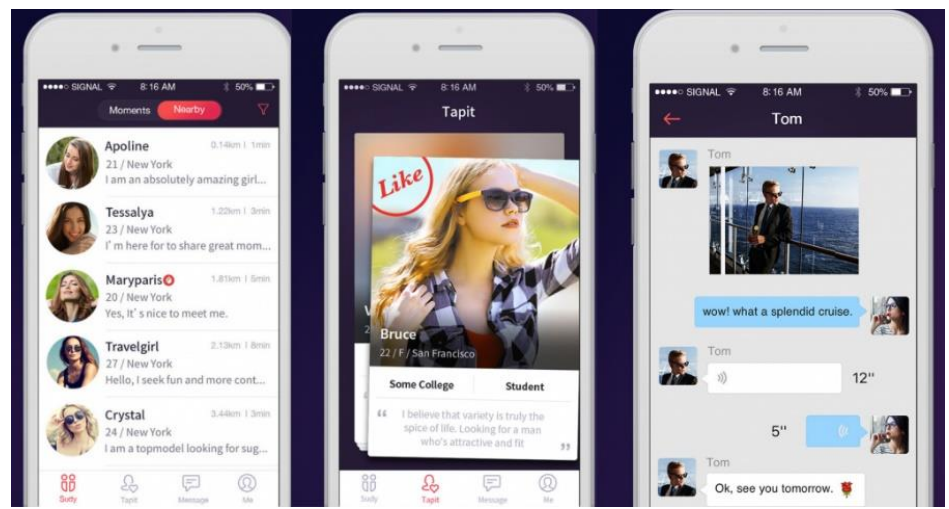

Fuente: Sugar Daddy (2018).

En la prostitución queda claro que el encuentro físico no puede ser sustituido totalmente por la realidad online, ¿̇o tal vez sí? Internet posibilita también un consumo sexual meramente virtual, bien a través del consumo de pornografía (en el que nos centraremos en el epígrafe siguiente), bien a través de las diferentes formas de sexualidad virtual. 
Figura 5: Oferta de sexo virtual en Sevilla

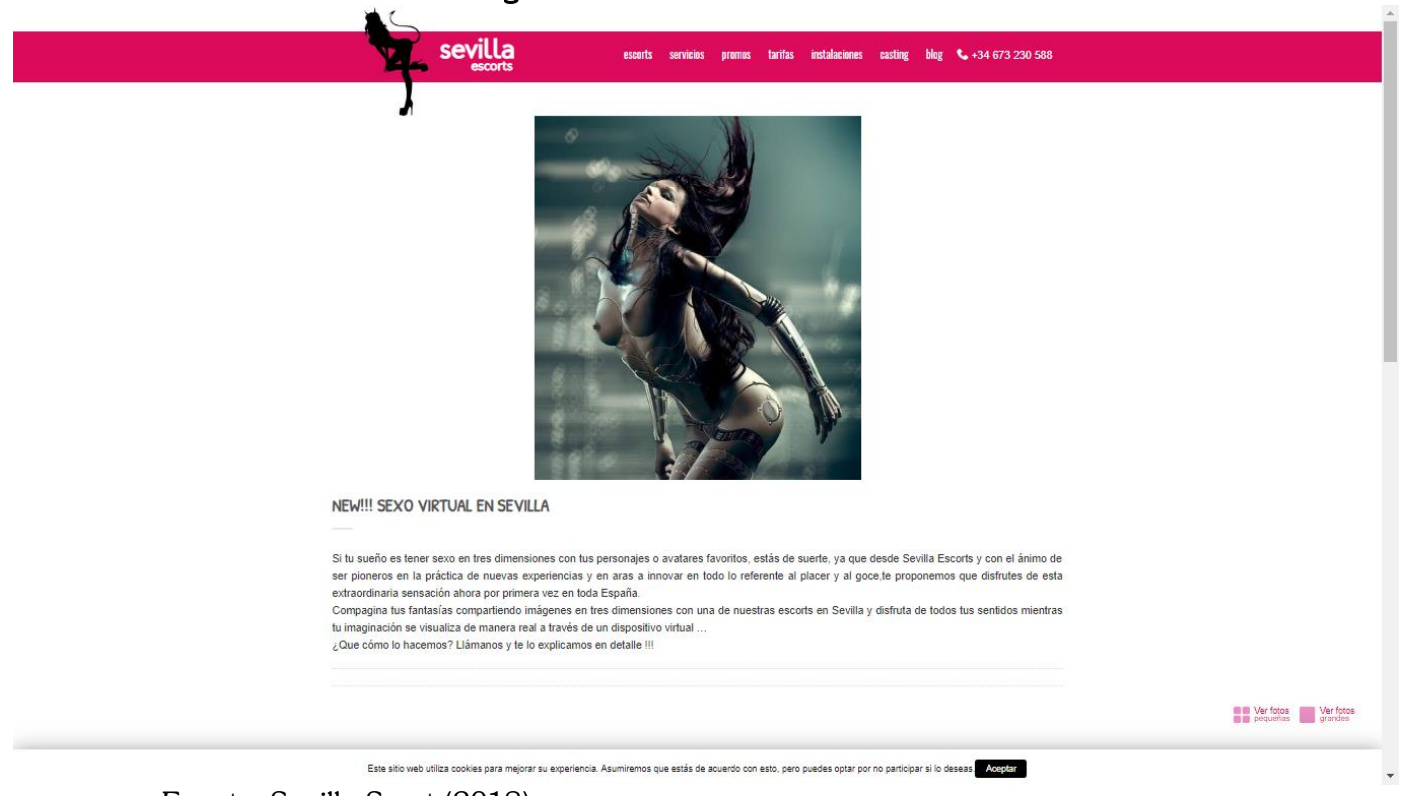

Fuente: Sevilla Scort (2018).

\section{Pornografía}

Las cifras de consumo de pornografía que proporcionan algunas empresas en internet son abrumadoras. Una de las más conocidas del sector Porno-Hub, realiza anualmente un estudio sobre el consumo de sus páginas, segregado por: sexo, países, horarios, medios utilizados (ordenador, internet...) ${ }^{1}$. Lejos de ser exhaustivos, nos interesan algunos datos relativos a 2016 que nos ayudan a entender la amplitud y características de este fenómeno.

\footnotetext{
${ }^{1}$ Para consultar los datos relativos a 2015 ver Pornhub's 2015 Year in Review. Los datos de 2016 pueden consultarse en: http://boingboing.net/2017/01/06/pornhubs-2016-year-in-revie.html. Última fecha de consulta 07 mayo 2017.
} 
El primer dato interesante tiene que ver precisamente con los medios utilizados. Progresivamente se afianza el consumo de pornografía desde el móvil en detrimento del ordenador, un hecho que se manifiesta especialmente entre los más jóvenes. El consumo de pornografía se produce más entre hombres que mujeres, aunque hay una progresiva incorporación de las mujeres (un 26 por ciento a nivel mundial).

Pornohub recibe 64 millones de visitas diarias y el tiempo total de visionado estaría en torno a las 4.599.000.000 horas. Pero más allá de las cifras que mueve este negocio o incluso de los porcentajes que ocupan estas páginas en la red, nos interesa aproximarnos a las características de los productos ofertados.

Los buscadores entrecruzan etiquetas hasta aproximar al máximo la oferta del producto a los usuarios específicos. Esto ha hecho que el número de categorías del porno se multipliquen exponencialmente (Valcuende del Río, Sierra, y Marco-Macarro, 2017). $\mathrm{Si}$ en etapas pasadas el cine o las revistas jugaron un papel pedagógico en relación con la sexualidad, hoy viejos y nuevos modelos de sexualidad son aprendidos a partir de internet. El crecimiento del consumo pornográfico en los móviles pone de manifiesto una búsqueda compulsiva de escenas, contextos o cuerpos. Tal y como señalan Valcuende del Río, Sierra y MarcoMacarro (2017) las tipologías de la pornografía que se ofertan en internet son innumerables, a partir de diversos elementos que permiten diferentes combinaciones. 
Figura 6: Tipologías de prácticas sexuales

\begin{abstract}
-los cuerpos ofertados: nacionalidad, raza, edad, características físicas -el número de participantes: individual, pareja, tríos, grupos....

-los tipos de prácticas: felación, penetración, masturbación, fetichismo, sexo grupal, exhibicionismo, voyerismo, sadismo, masoquismo, zoofilia....

-las relaciones de los participantes: familiares (incesto), relaciones de trabajo, desconocidos, etc.

-los contextos en los que se producen estas relaciones: casa, calle, ámbito laboral....
\end{abstract}

Fuente: elaboración propia.

La combinación de estas y otras características permite responder a prácticamente todas las fantasías de los potenciales consumidores. Internet se convierte así en una herramienta que contribuye a potenciar uno de los elementos de la sexualidad habitualmente olvidado y es su carácter teatral. Cualquier fantasía es posible en este inmenso escaparate.

Figura 7: Buscador XVideos

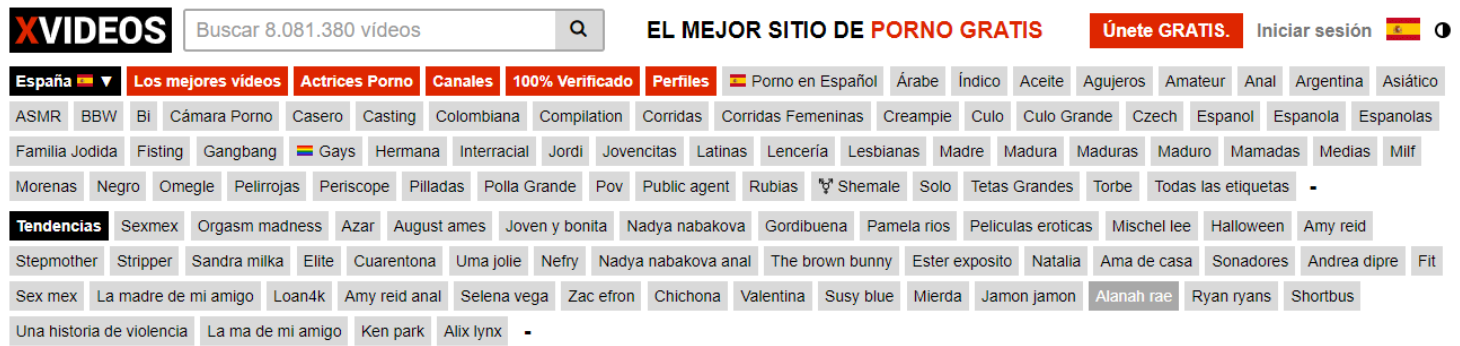

Fuente: XVideos (2018).

Ahora estas fantasías no sólo responden a una visión heteronormativa, independientemente de que la pornografía maistraising reproduzca el imaginario dominante. Las minorías sexuales pueden acceder a un consumo mucho más difícil en el mundo offline por las sanciones sociales, pero también los activistas pueden contestar la pornografía habitualmente comercializada (Smiraglia, 2012).

La necesidad de ampliar el mercado del sexo se sustenta, como cualquier oferta comercial, en las posibilidades de responder 
a la segmentación del mercado, proporcionando una variada oferta de cuerpos racializados/exotizados y prácticas disponibles para el consumo. Las imágenes ofertadas responden fundamentalmente a una perspectiva masculina y heteronormativa sobre la sexualidad, sea en la oferta destinada al mundo heterosexual como homosexual (Ariza, 2018a). Del mismo modo, la prostitución reproduce el imaginario racializado, un hecho que se evidencia especialmente en la pornografía interracial, y en los propios buscadores de internet que sexualizan de manera desigual las categorías raciales.

Figura 8: Primeras entradas del buscador Google con los términos de búsqueda "sexo y blancos"

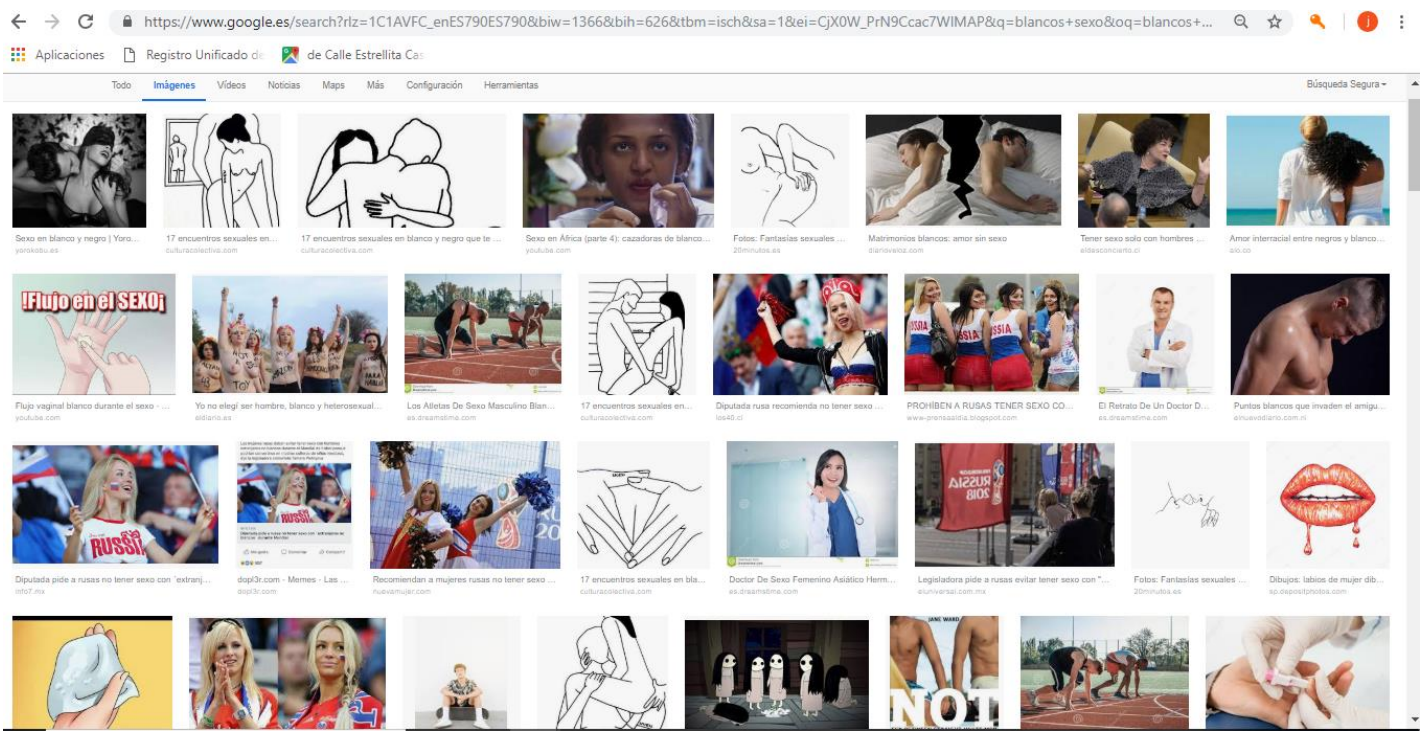

Fuente: Google (2018).

En la figura anterior vemos como en las primeras entradas de la búsqueda "sexo y blancos" en Google imágenes no aparece ninguna imagen de consumo pornográfico. Igualmente sucede si realizamos esta misma acción en el buscador general de Google, 
dónde de nuevo la pornografía está ausente. ¿Pero qué sucede si realizamos la búsqueda introduciendo el término "negros y sexo"?

Desde la primera imagen los negros son claramente sexuados y la pornografía se hace explícita en google imágenes. Igualmente sucede en el buscador general de Google. Ahora las entradas que aparecen en los primeros lugares serán las siguientes: "video porno interracial: sexos con negros...", "sexo con negrosporno gratis diario.", "sexo intenso de mujeres cachondas follando con negros". Las diez primeras entradas que asocian estos términos son todas pornográficas.

$\mathrm{Si}$ reproducimos la búsqueda introduciendo el término "asiáticos y sexo", sucede un fenómeno cuanto menos curioso. En el buscador general los resultados no hacen referencia a hombres, sino a mujeres, así entre los primeros resultados nos encontramos con: "video porno de asiáticas", "asiáticas follando...", "video porno de sexo gay asiático"; la cuarta referencia es "asiáticos gay follando" que nos remite a una página de pornografía gay. El buscador de imágenes nuevamente vincula "asiáticos" con "asiáticas", reproduciendo imágenes de pornografía de mujeres asiáticas o bien de hombres gais. La jerarquización corporal queda clara en las búsquedas, pero se reproduce nuevamente en la pornografía, en la que el cuerpo del negro es vinculado fundamentalmente con el pene, mientras que, en su extremo contrario, los asiáticos son los cuerpos más "feminizados". Si la racialización de los negros se representa en clave masculina, desde una corporalidad no controlada y amenazante, los asiáticos son representados en clave femenina, como "menos hombres", quedando claro un orden corporal (Valcuende del Río y Vásquez Andrade, 2014), en el que "lo blanco" y "lo masculino" representan el vértice del poder.

Ahora bien, si las herramientas de comunicación reproducen los imaginarios sexuales racializados y generizados, la pornografía online facilita también mostrar realidades que no se corresponden a los modelos heternormativos dominantes. Nunca como hasta ahora se han podido visualizar prácticas y opciones sexuales ocultas, reforzando la articulación de grupos que se englobarían en 
las sexualidades denominadas periféricas y disidentes. No por casualidad la investigación en este ámbito crece exponencialmente en cuanto que permite a los investigadores visualizar realidades que hasta ahora estaban ocultas o eran de muy difícil acceso, especialmente en los ámbitos considerados anormativos e incluso ilegales.

Junto a la pornografía profesional nos encontramos también el creciente peso de la pornografía amateur. En páginas como XVIDEOS los usuarios acceden a miles de películas pornográficas, pero también a las páginas personalizadas de otros usuarios que intercalan sus vídeos pornográficos preferidos, con fotografías personales $e$ incluso con sus propias grabaciones manteniendo relaciones sexuales. Habitualmente los rostros de los participantes permanecen ocultos. En otras ocasiones los rostros son visibles $e$ incluso se facilitan formas de contacto, lo que puede indicar que nos encontramos con formas de promocionarse en el ámbito del sexo de pago. Esto no sólo sucede en las páginas temáticas. Numerosos perfiles de Twitter comparten videos de los protagonistas y de otros usuarios realizando actos sexuales. Internet ha posibilitado que muchos usuarios se conviertan en "actores" pornográficos, posteriormente profundizaremos en este aspecto.

\section{Agencias de contactos y matrimoniales}

El acceso a una de las empresas con más difusión en el sector, eDarling, nos puede permitir analizar este tipo de oferta. En su página web se reproduce en cierta medida la imagen del amor romántico, que no es incompatible con la utilización de medios "científicos" que garantizan el éxito en la búsqueda del amor para toda la vida. Nos encontramos, como reza la propia publicidad, con una página para "solteros exigentes". A partir de la información proporcionada por los usuarios se realizan "test de 
personalidad" a través de los que: "eDarling te sugiere solo parejas que encajan contigo".

Hoy las posibilidades de encontrar pareja por internet se han ido asumiendo como algo habitual, un hecho que no sucede con las personas no socializadas en estos medios.

Figura 9: Agencia matrimonial
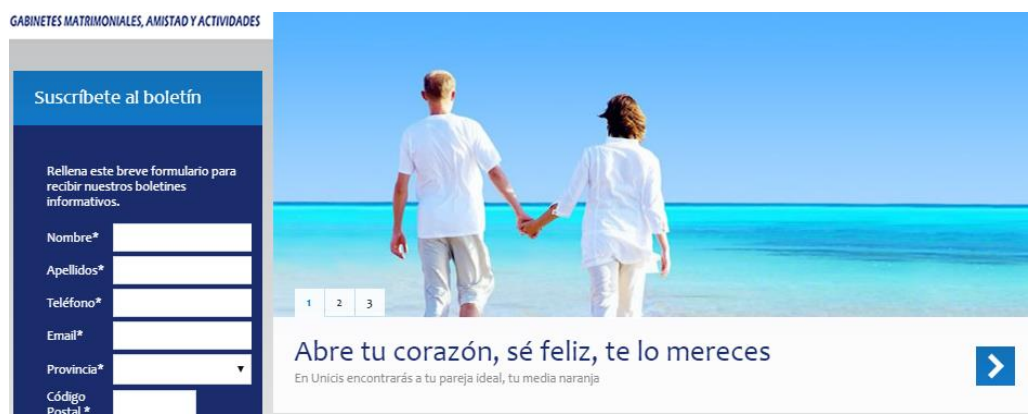

Fuente: Unicis (2018).

Figura 10: Captura de pantalla página de contactos.

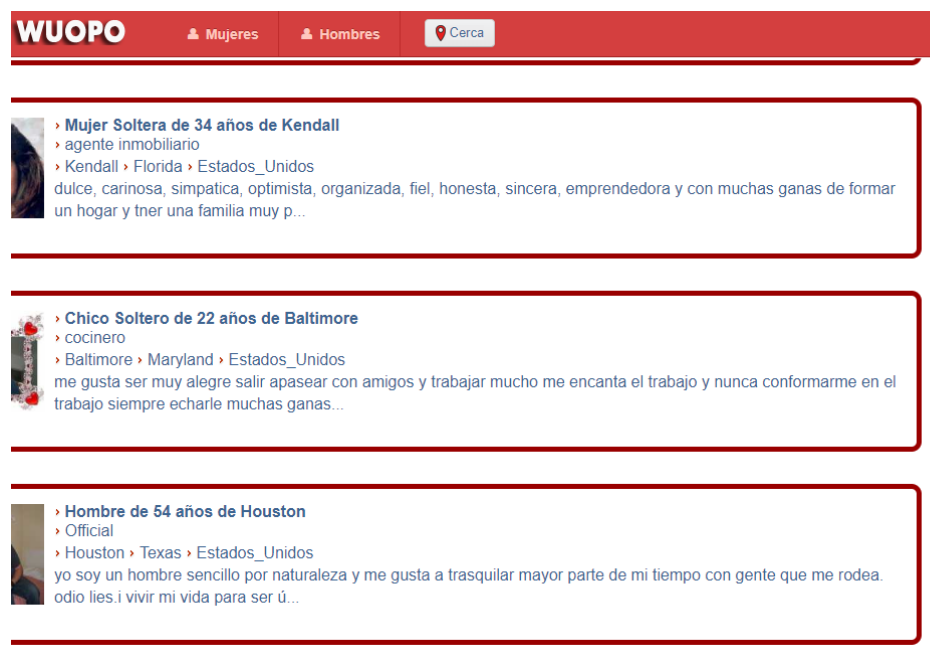

usamos cookies propias v de terceros dara meiorar el servicio. Al continuar naveoando acenta nuestra Dolitica de cookies cerrar Fuente: WUOPO (2018).

${ }^{2}$ Fuente: Web eDarling https://www.edarling.es/. Captura de pantalla (Fecha de consulta 07 mayo 2017). 
No es extraño que estas páginas web hagan un esfuerzo en la publicidad por naturalizar esta forma de conocer pareja.

¿Sabías que 1 de cada 4 parejas en España se conocieron por Internet? El desarrollo de las Nuevas Tecnologías hace que cada vez sea más normal conocer a alguien en la red. Nuestros usuarios son gente que no se conforma con cualquier cosa, buscan a alguien del que enamorarse de los pies a la cabeza. Gracias a nuestro test de compatibilidad en eDarling te ayudamos a conocer a esa persona que tanto tiempo llevas buscando ${ }^{3}$.

La aparente frialdad que supone acceder a un catálogo de potenciales parejas es recreada desde una visión romántica, eDarling nos oferta la posibilidad de "el amor verdadero". Algunas de las ventajas de la búsqueda de pareja por internet es evitar los posibles equívocos de los encuentros no programados y ahorrar tiempo. Como se señala en POF, una página pensada para "profesionales solteros": "iNo Vale la pena buscar en bares o supermercados, así que regístrate aquí!"

La globalización del mercado en general, y del mercado del sexo en particular, a través de internet ha supuesto la creación de negocios globales, como las agencias matrimoniales, que sobrepasan nuestro contexto cotidiano de interacción posibilitando contactar potenciales parejos en países diferentes. Internet se ha convertido en un cauce para promover los viajes y la migración (Pichardo, 2003; Roca, 2011).

Es interesante observar como las agencias matrimoniales especializan su oferta en función del lugar del planeta en el que operen, reproduciendo el imaginario de la mujer ideal adaptada a lo que se supone que busca el hombre. Así nos encontramos, por ejemplo, con agencias que conectan a mujeres de diversos países

\footnotetext{
${ }^{3}$ Página de eDarling: https://www.edarling.es/. Última fecha de consulta 07 mayo 2017.

4 Página http://www.pof.es/es landero.aspx?dating=es statslander01. Última fecha de consulta 07 mayo 2017
} 
latinoamericanos con hombres estadounidense o bien agencias que se han especializado en ofertar mujeres del Este de Europa para otros hombres de países europeos. Conviene que nos detengamos en alguna de estas páginas.

Figura 11: - Agencia matrimonial internacional.

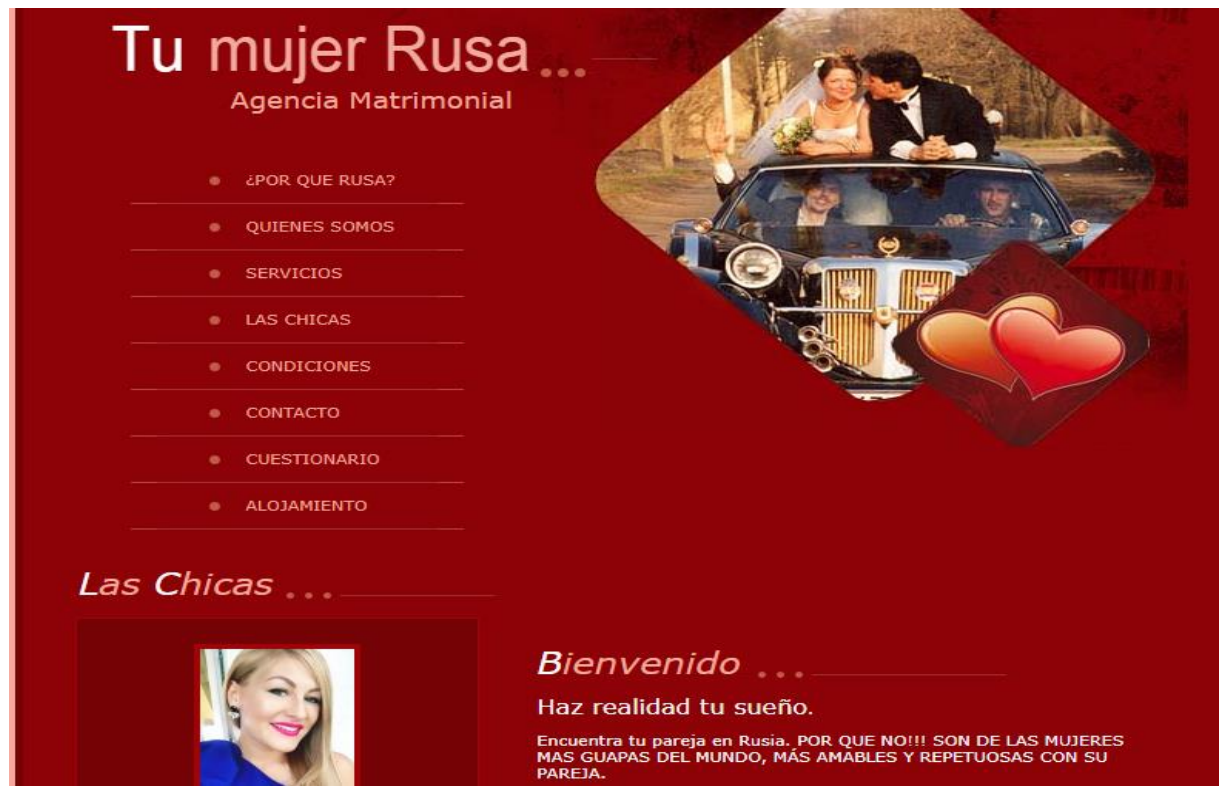

Fuente: Agencia Tu Mujer Rusa (2018).

"Tu mujer rusa" oferta mujeres rusas para españoles, con fines matrimoniales. La propia agencia publicita las bondades de una mujer que responde al ideal "soñado" de feminidad: joven, bella, fiel, "femenina", familiar, a la que poco le importa la edad y el físico del hombre:

¿Por qué Rusa?

Las mujeres rusas son consideradas de las más guapas del mundo.

Son cariñosas, educadas y familiares. Son fieles y para ellas su hombre es muy importante en su vida. Sus costumbres y 
formas de pensar son totalmente distintas a la mujer española.

Podríamos decir que para el hombre español son la pareja perfecta. Para el carácter de la mujer rusa la diferencia de edad no es tan importante como en España. Es habitual, encontrar parejas con una diferencia de edad superior a la media Española.

Muy importante para la mujer rusa, es ser tratada con cariño, respeto y amor. En Rusia las mujeres están faltas de estos sentimientos. Un hombre educado y cariñoso y fiel se gana su respeto con facilidad.

Además la mejor calidad de vida en España, el clima cálido y la hospitalidad de nuestro país son alicientes para que estas chicas decidan cambiar de vida (Agencia matrimonial Tu Mujer Rusa, 2018).

La agencia ofrece un amplio catálogo de chicas, proporcionando fotografías y algunas de sus características: edad, estatura, peso, si tiene o no hijos, estado civil, si fuma o no, ciudad, color de pelo y ojos, nivel de estudios, profesión, intereses, carácter y expectativas. Una vez que el hombre se pone en contacto, la empresa le ofrece diversas posibilidades de encuentro, bien a través del traslado de la chica a España o del desplazamiento del solicitante a Rusia, lo que le permitirá conocer a varias candidatas. Ahora bien, de forma previa el cliente (término que es evitado en todo momento) enviará fotografías y cumplimentará un cuestionario "Debemos garantizar a las chicas que la persona que la invita sea una buena persona que realmente busca una relación seria". La información requerida a los usuarios es la misma que se solicita a la chica, aunque se añade una información complementaria: si quiere o no hijos, describir su forma de vida y las características de la chica que le gustaría como posible pareja estable. 
Figura 12: Publicidad agencia matrimonial internacional

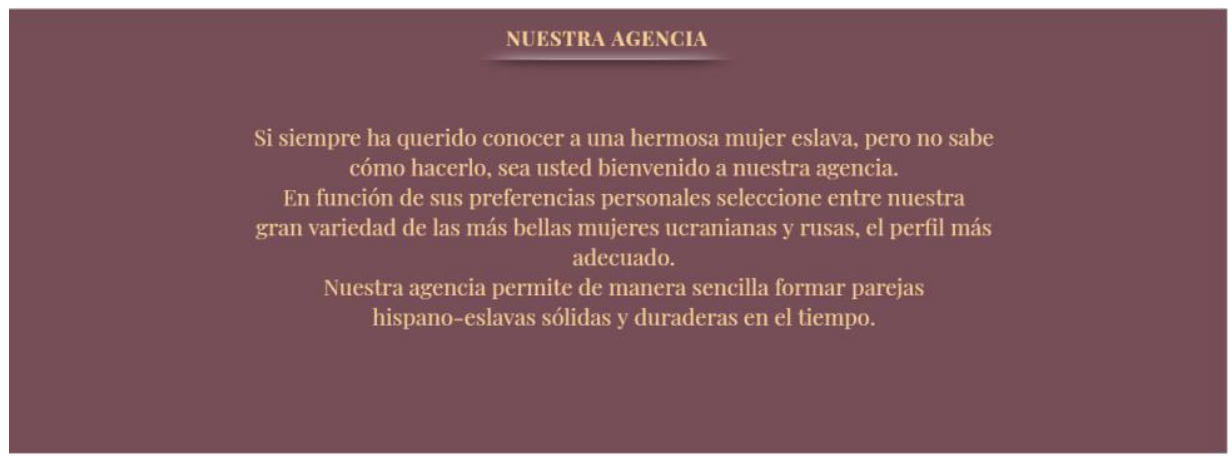

Fuente: Eslava Agencia (2018).

\section{El sexo esporádico}

Junto a las aplicaciones que ofertan relaciones estables, nos encontramos con otras páginas pensadas para relaciones esporádicas. En este caso los mensajes son mucho más directo y explícitos:

Mediante esta 'app', accedes a una especie de mercado online en el que puedes ir añadiendo chicos a tu carrito. Su funcionamiento se basa en tres parámetros básicos: la geolocalización, la búsqueda por 'hashtags' para afinar las coincidencias con esa presunta media naranja y el 'gogolito', un motor de búsqueda semántica para los más exigentes. ${ }^{5}$

Elige, selecciona y consume con el mínimo esfuerzo y en el menor tiempo posible. Estos tres principios son fundamentales en las relaciones que se ofertan en internet, especialmente en los contactos esporádicos. En Mujer.com se refieren a Goog2Go como una aplicación que:

${ }^{5}$ https://itunes.apple.com/es/app/adoptauntio/id664639566? $\mathrm{mt}=8 \& \mathrm{ls}=1$. Última fecha de consulta: 06 mayo 2017. 
[...] está diseñada "para facilitar la comunicación entre dos adultos con el fin de minimizar situaciones incómodas antes de tener sexo consentido entre ambas partes. La app pide a ambas partes que describan su estado higiénico y sus niveles de alcohol en tiempo real, así las ambas partes tendrán la posibilidad de aceptar o no tener sexo con esa persona. $^{6}$

La distancia permite jugar con la representación y la adquisición de diferentes máscaras, un hecho que evidentemente sucede también en la realidad offline pero que en estos contextos se ve agudizado, como se puede evidenciar en un ámbito que excede a este artículo como son los usos delictivos de la red. Los actores muestran los elementos que les hacen especialmente atractivos en función de las imágenes dominantes que posibilitan el encuentro sexual, aunque la evolución de las propias TIC ha supuesto un cambio en las formas del "cortejo", desplazando progresivamente el peso de la palabra a la imagen.

En los chats pensados para propiciar el encuentro sexual, la palabra escrita juega un papel fundamental, como señala Peplo (2013) en la investigación realizada en un chat gay en la ciudad de Villamaría, Córdoba (Argentina), los participantes deben atraer, de entrada, el interés de las personas que participan en el propio chat. Para ello el nickname es fundamental. A través del nombre adoptado es preciso fijar la atención del resto de usuarios, indicando el lugar (por lo que es habitual que en estos chats se refieran en el nombre a la localización), las preferencias sexuales (pasivo, activo, versátil, gay, heterosexual...) o los elementos corporales que puedan atraer al resto de los usuarios (Peplo, 2013). Sin embargo, a medida que los chats proporcionan la posibilidad de conectarse por cámara o que hay otro tipo de aplicaciones (Skype, Facebook, Whatshapp...) que facilitan que los usuarios se vean, el chat escrito será la fase inicial para un encuentro que

614 APPS para ligar una de propina para tener sexo. En Mujer.com http://www.mujerhoy.com/psico-sexo/sexo/apps-para-ligar-smartphone-

833855102014.html. Fecha de consulta: 08 mayo 2017. 
terminará en el uso de otras aplicaciones o de las herramientas proporcionadas por el propio chat que posibilita el intercambio de imágenes.

Pero no siempre es la palabra el inicio de la relación, el desarrollo de determinadas apps permite que el encuentro se realice de forma inversa. Primero será la imagen y posteriormente será la palabra a partir de la que se negocie la posibilidad del encuentro, el peso de apps como Tinder evidencia esta tendencia. Son infinidad las aplicaciones en la que las personas pueden mostrar tanto las características físicas como las opciones sexuales. Desde páginas destinadas a encuentros sexuales heterosexuales a páginas para homosexuales e incluso aplicaciones especializadas en prácticas concretas conforman un nuevo contexto de interacción en el que la teatralidad gana peso, permitiendo seleccionar aquellos aspectos que se consideran más deseables y jugando con toda una serie de papeles, que fomentan la proliferación de "nuevas" identidades, que reproducen las visiones más tradicionales de la sexualidad, veamos un ejemplo. En el ámbito de los hombres que mantienen relaciones sexuales con otros hombres las imágenes que más cotizan en el mercado sexual son aquellas que responden a la masculinidad heterosexual, esto ha promovido la creación de etiquetas como la del "heterosexual curioso", y es que tal y como nos recuerda Sabuco y Valcuende del Río (2003) la "cultura gay" es habitualmente una imagen hiperbólica de la masculinidad, e internet da fe de ello (ver Ariza, 2018b). El mundo online permite la proliferación no sólo de diversas imágenes sino también la posibilidad de mantener vidas paralelas entre contextos heteronormativos y contextos que posibilitan escapar al control de la cotidianidad offline. No es extraño que sean los grupos minorizados los que han encontrado en el mundo online un contexto especialmente propicio para mantener relaciones sexuales, en cuanto que les garantiza una cierta separación del mundo offline. Como señala el activista gay español Sangay Lily: 
$\mathrm{Si}$, ya teníamos mucha práctica con el sexo anónimo esporádico. Básicamente porque hasta entonces era el único posible para la mayoría que mantenía oculta su sexualidad: eludir el riesgo de la identificación/localización huyendo de entornos cerrados, identificables, específicos. Así que los novedosos chats de internet, con su oferta de espacios virtuales imposibles de aprehender físicamente, en realidad ampliaron estrategias ya archiconocidas para nuestra comunidad: el riesgo de buscar sexo en un lugar público, que paradójicamente, garantizaba esquivar la identificación. Esas rutinas de riesgo/esquive ya nos habían preparado excepcionalmente para un medio como internet (Shangay Lily, 2016:195).

Ahora bien, internet no es una realidad estática, las transformaciones que se han producido desde sus inicios hasta la fecha son espectaculares, también en el ámbito de la sexualidad. Si en una buena parte de estas redes y aplicaciones tienen como objeto el encuentro físico, nos encontramos también con aplicaciones que fomentan una sexualidad meramente virtual, en las que se pone de manifiesto la concepción mercantilizada de las relaciones a nivel general y de las relaciones sexuales en particular. Este es el caso de las conocidas "ruletas", como Dirtyroulette, donde el usuario puede ser visualizado a través de su cámara web y al mismo tiempo puede acceder por unos instantes a las imágenes de otras personas. Si la "mercancía" no gusta se irá pasando de uno a otro usuario hasta que los participantes deciden detenerse y entablar una conversación, que puede o no terminar en una relación de carácter sexual. Es la imagen la que evidentemente hace que el usuario pase a otro usuario o permanezca, posteriormente será la palabra escrita o bien la oralidad a través del micrófono las que entren en escena. En este caso estas ruletas conectan "el mundo" pudiéndose seleccionar los usuarios por países y dejando al azar las personas que entran en las pantallas del ordenador.

Pero sin duda, las aplicaciones en las que se pone más claramente de manifiesto el cambio de significación de la 
sexualidad a partir de internet son sitios web como Cam4. La web, en función de las preferencias sexuales, permite acceder a hombres, mujeres, parejas..., que se exhiben públicamente retransmitiendo en directo. El atractivo fundamental de estas páginas no sólo estriba en facilitar el deseo voyeur y exhibicionista de los participantes, sino fundamentalmente en la supuesta autenticidad a tiempo real. El observador no sólo puede ver la acción, sino que también puede formar parte de la misma a partir de los chats, que generan una interacción inmediata con los "actores". De esta forma se establece una negociación de la acción, tanto en los "amateur" como en los "profesionales" que no sólo están para exhibirse, sino que además tienen la posibilidad de ganar dinero a partir de los denominados "tokes" o "regalos".

$\mathrm{Si}$ es cierto que algunas de las funciones de la web son gratuitas y que algunas personas no cobran, también lo es que este medio se ha convertido en un buen negocio tanto para la empresa que la gestiona como para las personas que buscan algunos ingresos extraordinarios a partir de eso que se denomina economía colaborativa, que ha experimentado una auténtica explosión no sólo en el ámbito del sexo (Rosth, 2016) sino también en el alquiler de casas, de vehículos, etc, convirtiendo los contextos privados en ámbitos públicos que posibilitan un negocio desregulado a partir del cual los trabajadores se convierten en "autónomos" o como gusta decir el neolenguaje oficial en "emprendedores", también de sus propios cuerpos, algo especialmente tentador para aquellos que sólo tienen su cuerpo como recurso económico.

Las personas que interactúan en estas páginas sexuales negocian lo qué va a hacer, cómo se va a hacer y con quién (espectáculos privados o públicos). Un caso más que plantea una difusa separación entre lo que es y no es prostitución, y en el que la negociación como nos recuerda Rost (2016) no es sólo una forma de comprar interacciones sexuales, sino que el proceso forma parte de las propias relaciones sexuales. El ejercicio de seducción consiste en que la persona o personas que se muestran públicamente puedan ir haciendo que las personas que los 
visionan vayan proporcionando "tokes" para ir cumpliendo las fantasías sexuales de los que observan. Para las personas que visualizan estas páginas lo fundamental es poder ver las partes corporales que ellos desean ver o propiciar que se realicen las prácticas sexuales que les gustaría ver en el menor tiempo posible. Para los que se exhiben es fundamental prolongar las escenas para recibir el mayor número de toques que se traducen en dinero. Un ejercicio de seducción, en el que el dinero empleado es fundamental para lo que de forma un tanto forzada podríamos denominar como "galanteo".

Esta articulación entre sexualidad y herramientas propuesta por Rost (2016) es una perspectiva especialmente interesante, ya que vincula las formas de interacción con la propia acción, que se nos muestra como un todo inseparable. Desde este planteamiento el proceso de comunicación especifico que definen las propias herramientas forma parte del juego de la seducción o si se quiere de la propia teatralidad de la sexualidad.

El intercambio de imágenes con connotaciones sexuales comienza a ser una práctica habitual especialmente en la generación que ha sido socializada en las TIC, surgiendo una nueva terminología que pone de manifiesto la centralidad de lo visual como forma para propiciar el encuentro sexual o bien como una forma de sexualidad en sí misma (sexting). El desarrollo de algunas apps, precisamente ha facilitado el intercambio de imágenes también de carácter sexual, especialmente entre jóvenes $y$ adolescentes. El Snapchat que posibilita el intercambio de imágenes perecederas, que sólo pueden ser visionadas durante segundos, ha contribuido al desarrollo de estas formas de relación sexual, que difuminan las fronteras entre la sexualidad virtual y la sexualidad física ${ }^{7}$.

${ }^{7}$ Para un análisis más en profundidad sobre el sexting y el Snapchat ver el trabajo de Ribes Hernández (2016). 


\section{Conclusiones}

El erotismo, la pornografía, la venta de servicios sexuales o el intercambio sexual, son una realidad constante en internet. Ahora bien, el análisis que hemos realizado sobre la pornografía y la prostitución en el mundo online evidencia su imbricación con el mundo offline. El peso de las TIC ha transformado no sólo la significación de muchos de los espacios físicos en los que se realizaban los intercambios sexuales, también ha modificado las estrategias de los trabajadores sexuales, que pueden acceder a un mercado globalizado en función de la demanda; de la misma forma que los usuarios encuentran una amplia oferta que se ajusta a sus "necesidades". Y es que una de las grandes virtualidades de las TIC es precisamente la capacidad de ofertar un amplísimo catálogo de productos y servicios, a los que podemos acceder desde la comodidad de nuestros ordenadores y móviles.

El mercado en general, y el mercado sexual en particular, es accesible y cómodo para cualquier usuario, que puede planificar la compra de sexo pagado, bien en su cotidianidad o bien en contextos lejanos. Los destinos sexuales se ven potenciados al hacerse presentes en el mundo online. Los trabajadores $y$ trabajadoras sexuales son previamente conocidos y contactados antes de realizar el viaje, pero también sus servicios pueden ser demandados más allá de sus lugares de residencia habitual.

De la misma forma, la globalización del mercado sexual ha posibilitado también la aparición de negocios como las agencias matrimoniales internacionales que evidencian la reproducción de las desigualdades y la creación de mercados de mujeres "perfectas" y "necesitadas" para los hombres del primer mundo. Internet posibilita una interconexión global y nuevas formas de atravesar las fronteras para las personas con menos recursos. La conexión a través del mundo online contribuye a potenciar nuevas estrategias de atravesar las fronteras físicas.

Parece claro que internet ha contribuido a expandir diversos negocios sustentados en la venta de cuerpos y afectos, pero también a generar un mundo de fantasías corporales que 
sustentan el pujante negocio de la pornografía. La pornografía puede consumirse a la carta habitualmente reproduciendo el imaginario sexual dominante, pero también subvirtiendo las sexualidades estandarizadas. Las minorías sexuales han encontrado en internet ámbitos especialmente propicios no sólo para consumir una pornografía que se adecua a sus gustos, sino también para encontrar ámbitos de encuentro y reunión con aquellos que no responden a las sexualidades normativas. Internet parece jugar un papel fundamental en la expansión de una infinidad de categorías vinculadas al sexo y a las prácticas sexuales. Desde este planteamiento el mundo online ha contribuido de una forma fundamental no sólo a la expansión de "identidades" sexuales sino también al desarrollo de nuevos segmentos del mercado con necesidades específicas. Las identificaciones más que nunca pueden ser mercantilizadas, lo que se traduce en la práctica en la conformación de nuevos nichos de consumidores.

Sin embargo, en los fenómenos descritos hasta el momento nos encontramos, en cierta medida, una continuidad entre el mundo online y el mundo offline, ahora bien, en otros aspectos, el desarrollo de internet y las apps ha supuesto una modificación sustancial en las formas de interacción sexual a diversos niveles. La visión mercantil permea en buena medida también los intercambios sexuales no pagados. Los usuarios de algunas aplicaciones que buscan relaciones esporádicas pueden acceder y formar parte de amplios catálogos que ofertan cuerpos a la carta. Estas aplicaciones permiten acceder a fotos, gustos sexuales, distancia y disponibilidad. El consumo de sexualidad se produce de una forma directa, no es extraño que nuevamente los espacios físicos hayan modificado sustancialmente la significación. La forma más rápida y eficaz para conseguir una relación sexual se produce ahora a partir de internet. Si bien es verdad que este tipo de encuentros habitualmente terminan en un contexto físico, 
también lo es que los contextos físicos en cierta medida han sido virtualizados ${ }^{8}$.

Cada aplicación proporciona la información que requieren los participantes en función de la acción. Desde una información más o menos exhaustiva en aquellas páginas en las que se buscan relaciones estables, a una información basada fundamentalmente en la corporalidad y los gustos sexuales en las aplicaciones diseñadas para encuentros casuales. Si en las aplicaciones que ofertan la posibilidad de establecer relaciones estables la corporalidad es un factor importante, también lo son otros factores como el estatus económico.

Pero sin duda dónde más se ponen de manifiesto las especificidades del mundo online están relacionadas con el sexo virtual o cibersexo. Es precisamente este tipo de prácticas las que cuestionan algunos de los principios en los que se sustentaban habitualmente las relaciones sexuales offline y las formas en las que se desarrollaban las prácticas sexuales. En el consumo tradicional de la pornografía el usuario era un receptor que se diferenciaba claramente de los actores. En algunas de las aplicaciones del mundo online el papel del receptor y del actor se confunden, de la misma forma que se difuminan los límites entre lo íntimo y lo público. Las relaciones sexuales que se generan en el mundo online tienen sus propias normas que se sustentan fundamentalmente en la imagen. El mundo virtual posibilita el encuentro sexual con personas conocidas, pero también abre la posibilidad a encuentros con desconocidos, algo que preocupa especialmente en el caso de los adolescentes por el riesgo que conlleva este tipo de prácticas, pero que más allá de los problemas legales y morales, evidencian nuevas formas de entender el consumo del sexo, produciéndose un claro corte generacional, entre aquellos que se han socializado en este medio y las generaciones que han entrado de forma más tardía en el mundo

\footnotetext{
${ }^{8}$ Para un análisis de las trasformaciones de los contextos físicos offline, así como el debate en torno a si internet representa la conformación de un nuevo espacio, ver Gómez (2003).
} 
online. Un mundo que es el principio de transformaciones más radicales que se anuncian a partir del avance de la robótica pero especialmente a partir del desarrollo de la realidad aumentada, en la que la falsa dicotomía entre mundo online y mundo offline parece difuminarse definitivamente.

Recordemos las palabras de Le Bretón (2002), el cuerpo se ha fetichizado, y efectivamente el mundo online visibiliza un inmenso escaparate de fetiches, que sustenta un negocio basado en la venta y el intercambio, pagado o no, de cuerpos listos para el consumo.

\section{Referências bibliográficas}

AGENCIA TU MUJER RUSA. Agencia matrimonial internacional. 2018. [http://www.tumujerrusa.com/ - fecha de consulta $23 \mathrm{dez} .2018$ ].

ARIZA, Saul. Homosexuality as Practice and the Social Implications of Representation, Studies in Gender and Sexuality, 19:4, pp.291-303, 2018a. DOI:10.1080/15240657.2018.1531543.

ARIZA, Saul. Las plumas son para las gallinas: masculinidad, plumofobia y discreción entre hombres. Revista de Dialectogía y Tradiciones Populares, v. LXXIII, n. 2, pp.453-470, julio-diciembre 2018b. DOI_ 10.3989/rdtp.2018.02.009

AVILÉS MARTÍNEZ, J. Ciberbullying: diferencias entre el alumnado de secundaria. Boletín de Psicología (96), 2009, pp.79-96 [https://www.uv.es/seoane/boletin/previos/N96-6.pdf - fecha de consulta 09 oct. 2020].

BUELGA, S.; CAVA, M. J.; MUSITU, G. Cyberbullying: victimización entre adolescentes a través del teléfono móvil y de Internet.

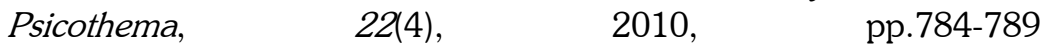
[http://www.psicothema.com/pdf/3802.pdf - fecha de consulta: 09 oct. 2020].

BUTLER, Judith, Cuerpos que importan. Sobre los límites materiales y discursivos del "sexo". Buenos Aires, Paidós, 2002.

BUTLER, Judith. Vida precaria. El poder del duelo y la violencia. Buenos Aires, Paidós, 2006. 
CASTELL, Manuel. Internet y la Sociedad en Red: Conferencia de Presentación del Programa de Doctorado sobre la Sociedad de la Información y el Conocimiento. Universitat Oberta de Catalunya. 2000. [https://www.uoc.edu/web/cat/articles/castells/castellsmain2.html - fecha de consulta: $18 \mathrm{dez}$. 2018].

CELORIO, Mariana. El amor a través de Internet en la sociedad de rendimiento, Dimensión económica, Instituto de Investigaciones Económicas, v. 1, n. 1, septiembre-diciembre 2009 [http://revistas.unam.mx/index.php/rde/article/view/19319 - fecha de consulta: 09 oct 2020].

CLUA, Anna. La batalla simbólica de las prostitutas. El papel de la comunicación. Revista Internacional de Comunicación y Desarrollo, (1), 2015, pp.139-150 [https://dialnet.unirioja.es/servlet/articulo?codigo $=4981142$ - fecha de consulta: 10 oct 2020].

COCA-PÉREZ Agustín, CÁCERES FERIA, Rafael, VALCUENDE DEL RÍO, José María. Human-animal sexual relations and the construction of masculinity in livestock farming contexts: The case of Andalusia (Spain). Sexualities. 2019;22(7-8):1017-1034.

DOI https://doi.org/10.1177/1363460718790886

DIÁRIO ON LINE. Sugar Daddy: "amor, dinero y placer" en el mundo de los encuentros. 2018. [https://www.diarioonline.com.br/tedoide/curiosidades/noticia488413-sugar-daddy-prostituicao-executiva-tem-aplicativo-paramulheres-que-querem-patrocinio.html. - fecha de consulta 10 nov. 2018].

ELEGANCY MODELS. Páginas de "escort" en Madrid. Luxury Scort Agency. 2018. [https://www.elegancymodels.com/escorts-madrid/ fecha de consulta 12 dez. 2018].

ESCOBAR, Arturo. Bem-vindos à Cyberia: notas para uma antropolo. Políticas Etnográficas no Campo da Ciberculturagía da cibercultura. En: SEGATA, Jean; RIFIOTIS, Theophilos (orgs.). Políticas Etnográficas no Campo da Cibercultura, pp: 21-66. Brasilia, ABA, 2016

[http://www.portal.abant.org.br/publicacoes2/livros/Pol\%C3\%ADticas Etnogr\%C3\%A1ficas no Campo da_Cibercultura.pdf - fecha de consulta: 10 oct 2020]. 
ESLAVA AGÊNCIA. Publicidad agencia matrimonial internacional Eslava. Agencia Matrimonial internacional. 2018. [https://www.eslavaagencia.com - fecha de consulta 28 dez. 2018].

FAJARDO CALDERA, M. I.; GORDILLO HERNÁNDEZ, M.; REGALADO CUENCA, A. B. Sexting: Nuevos usos de la tecnología y la sexualidad en adolescentes. International Journal of Developmental and Educational Psychology. INFAD Revista de Psicología, 1(1), 2013, $\quad$ pp.521-534 [https://www.redalyc.org/pdf/3498/349852058045.pdf - fecha de consulta: 09 oct 2020].

GARCÍA-PINA, C. A. Riesgos del uso de internet por niños y adolescentes. Estrategias de seguridad. Acta Pediátrica de México, 29(5), 2008, pp.273-279 [https://www.redalyc.org/pdf/4236/423640313006.pdf - fecha de consulta: 09 oct 2020].

GAROTOS.COM. "Acompañantes" masculinos. 2018. [https://garotos.com.br/ - fecha de consulta $10 \mathrm{dez}$. 2018].

GIDDENS, Anthony. Modernidad e identidad del yo: el yo y la sociedad en la época contemporánea, Barcelona, Península, 1997.

GÓMEZ CRUZ, Edgar. Cibersexo ¿La última frontera del eros? Colima, Universidad de Colima, 2003.

GOOGLE. Primeras entradas de Google imágenes con los términos "sexo y negros". 2018. [https://Google.com - Captura de pantalla con fecha 26 nov. 2018].

GOOGLE. Primeras entradas del buscador Google con los términos de búsqueda "sexo y blancos" 2018. [https://Google.com - fecha de consulta 26 nov. 2018].

GUASCH, Oscar; LIZARDO, Eduardo Chaperos. Precariado y prostitución homosexual. Barcelona, Ediciones Bellatera, 2017.

HARAWAY, Donna. Manifiesto Ciborg. El sueño irónico de un lenguaje común para las mujeres en el circuito integrado, 1984. [http://xenero.webs.uvigo.es/profesorado/beatriz_suarez/ciborg.pdf fecha de consulta 2 mayo 2016].

JIMÉNEZ, A. G. Una perspectiva sobre los riesgos y usos de internet en la adolescencia. Revista ICONO14. Revista cientifica de 
Comunicación y Tecnologías emergentes, 9(3), 2011, pp.410-425. DOI: https://doi.org/10.7195/ri14.v9i3.62

KAVANAUGH, PR; MARATEA, RJ. Identity, Resistance and Moderation in an Online Community of Zoosexuals. Sexualities, 19(1-2), 2016, pp.3-24. DOI: https://doi.org/10.1177/1363460715583585

LATOUR, B. Z. Reensamblar lo social. Una introducción a la teoría del actor-red. Buenos Aires, Manantial, 2005.

LATOUR, B.; RIFIOTIS, T.; PETRY, D. F.; SEGATA, J. Faturas/Fraturas: da noção de rede à noção de vínculo. Ilha Revista de Antropologia, 172), 2015, pp.123-146. DOI: https://doi.org/10.5007/2175$8034.2015 \mathrm{v} 17 \mathrm{n} 2 \mathrm{p} 123$

Le BRETON, David. Antropología del cuerpo y modernidad. Buenos Aires, Nueva Visión, 2002.

Le BRETON, David. Elogio del caminar. Siruela, 2017.

MENJIBAR. M. El sexting y 1@s nativ@s neo-tecnologic@s: apuntes para una contextualización al inicio del siglo XXI. Revista Electrónica Actualidades Investigativas en Educación, 10(2), 2010, pp.1-23 [https://www.redalyc.org/pdf/447/44717910026.pdf - fecha de consulta: 09 oct 2020].

MILKOSCI, Richard. Desejos digitais. Uma analise sociológica da busca por parceiros en internet, Rio de Janeiro, Editorial Argos, 2017.

ORTEGA-BARÓN, J.; BUELGA, S.; CAVA, M. J.; TORRALBA, E. Violencia escolar y actitud hacia la autoridad de estudiantes agresores de cyberbullying. Revista de Psicodidáctica, 22(1), 2017, pp.23-28. DOI: 10.1387/RevPsicodidact.16398

PEPLO, Fernando Franco. Notas para reflexionar acerca de las identidades (sexuales) de varones que socializan mediante internet. III Jornadas del Centro Interdisciplinario de Investigaciones en Género. 25 al 27 de septiembre de 2013 [https://core.ac.uk/download/pdf/34693316.pdf - Fecha de consulta: 09 julio 2020].

PÉREZ SANTANA, Gisela. Visibilizando las invisibilidades o cómo darle la vuelta a la tortilla. En: VALCUENDE del RíO, José María; MARCOMACARRO, María; ALARCÓN, David (org.). Diversidad Sexual en Iberoamérica. Sevilla, Aconcagua, 2013, pp.303-314. 
PICHARDO, José Ignacio. Migraciones y Opción Sexual. En GUASCH, Oscar; VIÑUALES, Olga. Sexualidades. Diversidad y control social. Bellaterra, Barcelona, 2003, pp.277-297.

PISCITELLI, Adriana. Trânsitos: brasileiras nos mercados transnacionais do sexo. Rio de Janeiro, Ed. UERJ, 2013.

RECIO, Félix. Identidad y Simulacro. Revista de Occidente, (56), 1986, pp. 46-52.

RIBES HERNÁNDEZ, Cristian. Análisis del comportamiento de los adolescentes desde el punto de vista del sexting en Snapchat. Tesis de Maestria. Universidad Politécnica de Valencia. Tutora: Marga Cabrera Méndez, 2016.

ROCA GIRONA, Jordi. Amores glocales, noviazgos transnacionales. La búsqueda virtual de pareja mixta por parte de hombres españoles. Revista de Antropología Social, 20, 2011, pp.263-292. DOI: https://doi.org/10.5209/rev_RASO.2011.v20.36269

ROST, Mariana. Sexualidades em negociação: a pornografia live streaming no CAM4.com. Tesis de maestría. Universidad de Vale dos Rios dos Sinos. Brasil, 2016.

RUIZ TORRES, Miquel. Pedofilia en Internet ¿Diversidad sexual o crimen? Diario de Campo. Suplemento, (26), Diversidad Sexual, México, CONACULTA-INAH. Agosto, 2003, pp.45-50.

SABATER, C.; LÓPEZ, L. Factores de riesgo en el Ciberbullying. Frecuencia y exposición de los datos personales en Internet. International Journal of Sociology of Education, 4(1), 2015, pp.1-25. : DOI: http://dx.doi.org/10.4471/rise.2015.01

SABUCO i CANTÓ, Assumpta; VALCUENDE del RÍO, José María. La homosexualidad como imagen hiperbólica de la masculinidad. En: VALCUENDE del RÍO, José María; BLANCO LÓPEZ, Juan (Edts). Hombres la Construcción Cultural de las Masculinidades. Madrid, TALASA 2003, pp.135-154.

SEGASTA, Jean; RIFIOTIS, Theophilos (orgs.). Políticas Etnográficas no Campo da Cibercultura, Brasilia, ABA, 2016.

SEVILLA-ESCORTS. Oferta de sexo virtual en Sevilla. 2018. [https://sevilla-escorts.com/escort/sexovirtual/ - fecha de consulta 18 dez. 2018]. 
SHANGAY, Lily. Adios, Chueca. Memorias del gaycapitalismo. La creación de la marca gay. Madrid, Editorial Foca, 2016.

SMIRAGLIA, Romina. Sexualidades de(s)generadas: Algunos apuntes sobre el postporno. Imagofagia. Revista de la asociación argentina de estudios de cine y audiovisual, (2), 2012 [file:///C:/Users/Usuario/Downloads/335-1135-1-PB.pdf. Fecha de consulta: 10 marzo 2020].

UNICIS. Agencia matrimonial Unicis. 2018. [http://www.unicis.es - fecha de consulta, $21 \mathrm{dez}$. 2018].

VALCUENDE del RÍO, José María; CÁCERES-FERIA, Rafael. Bricheros, sexo, raza y etnicidad en contextos turísticos. Revista de Estudios $\begin{array}{llll}\text { Sociales } & 49, & 2014, & \text { pp.72-86. }\end{array}$ http://dx.doi.org/10.7440/res49.2014.06

VALCUENDE del RÍO, José María; SIERRA, Rocío; MARCOMACARRO, María. Recreando espacios, tiempos y relaciones en internet. Revista Fórum Identidades, v. 23, 2017, pp.9-28. Fecha de consulta: 10 de enero de 2020.

VALCUENDE del RíO, José María; VÁSQUEZ ANDRADE, Piedad. Orden corporal y representaciones raciales, de clase y género en la ciudad de Cuenca (Ecuador). Chungara. Revista de Antropología $\begin{array}{lllll}\text { Chilena } & 48 & (2), \quad 2014, & \text { pp.301-317. DOI: }\end{array}$ http://dx.doi.org/10.4067/S0717-73562016005000008

VIVA LOCAL. Web de contactos. 2018. [http://www.vivalocal.com/acompanhante-erotico/br - fecha de consulta, 23 dez. 2018].

WILLIAMS CJ; WEINBERG, MS. Zoophilia in men: A study of sexual interest in animals. Archives of Sexual Behavior, 32(6), 2003, pp.523535. DOI: https://doi.org/10.1023/A:1026085410617

WUOPO. Captura de pantalla página de contactos. 2018. [https://www.wuopo.com/ - fecha de consulta, 22 out. 2018].

XVIDEOS. Buscador XVideos. 2018. [https://www.xvideos.com/ - fecha de consulta, 28 nov. 2018]. 